\title{
The Perception of Occupation by Hospital Nurses in Poland and Germany in Terms of the Risk of Excessive Stress and Burnout as Well as Possible Coping and Preventive Solutions
}

\author{
Dorota Kwiatkowska-Ciotucha $^{1}$, Urszula Załuska ${ }^{1}$ and Cyprian Kozyra ${ }^{2, *(D)}$ \\ 1 Department of Logistics, Wroclaw University of Economics and Business, 53-345 Wroclaw, Poland; \\ dorota.kwiatkowska@ue.wroc.pl (D.K.-C.); urszula.zaluska@ue.wroc.pl (U.Z.) \\ 2 Department of Statistics, Wroclaw University of Economics and Business, 53-345 Wroclaw, Poland \\ * Correspondence: cyprian.kozyra@ue.wroc.pl
}

Citation: Kwiatkowska-Ciotucha, D.; Załuska, U.; Kozyra, C. The

Perception of Occupation by Hospital Nurses in Poland and Germany in Terms of the Risk of Excessive Stress and Burnout as well as Possible Coping and Preventive Solutions. Int. J. Environ. Res. Public Health 2021, 18, 1797. https://doi.org/10.3390/ ijerph18041797

\section{Academic Editors: Emilia} Inmaculada De la Fuente-Solana,

\section{Guillermo A. Cañadas-De la}

Fuenteuis Albendín-García and José Luis Gómez-Urquiza

Received: 30 December 2020

Accepted: 8 February 2021

Published: 12 February 2021

Publisher's Note: MDPI stays neutral with regard to jurisdictional claims in published maps and institutional affiliations.

Copyright: (c) 2021 by the authors. Licensee MDPI, Basel, Switzerland. This article is an open access article distributed under the terms and conditions of the Creative Commons Attribution (CC BY) license (https:// creativecommons.org/licenses/by/ $4.0 /)$.

\begin{abstract}
Nurses constitute a professional group exposed to a high risk of stress and occupational burnout. Fewer nurses are recruited every year and the ever higher age of those professionally active is alarming. This article presents the results of international comparative studies from 2018 and 2019 involving Polish and German nurses (747 people) dedicated to the perception of aspects of nurses' work in terms of the risk of excessive stress and burnout and possible preventive measures. Using a proprietary questionnaire, the authors evaluated differences in the perception of the nursing profession in Poland and Germany, as well as in terms of seniority or decision-making. Next, the relationship between the perception of work specificity and opinions about professional risks and possible preventive measures was evaluated. The analysis used the Mann-Whitney U test and correlation analysis of the questions. Using exploratory factor analysis, the number of dimensions describing the nursing profession was reduced from 16 to four related to (1) workload, (2) job satisfaction, (3) atmosphere in the organisation and (4) sense of control over one's own work. The results showed statistically significant differences in the perception of professional specificity and risks according to the analysed characteristics.
\end{abstract}

Keywords: nursing profession; burnout prevention; working environment; primary research results; comparative analysis

\section{Introduction}

Contemporary concepts of occupational burnout define this phenomenon as a "disturbed professional relationship" between the individual and the individual's work and its related requirements [1]. People who perform the so-called helping professions, such as healthcare staff, teachers or caregivers of dependent people [2,3], are particularly vulnerable to such disturbances. The consequences of burnout are very serious both for the individual (demotivation, discouragement, desensitisation, poorer quality of services provided, mental problems) and for the organisation (low efficiency, lack of commitment, creativity, financial losses). This is the result of psychological phenomena causing burnout such as psychophysical and emotional exhaustion, depersonalisation and reduced evaluation of one's own achievements [4]. In the 21st century, the problem of burnout has been widely recognized. The results of research conducted in the USA and Canada confirmed the universality of this phenomenon and the possibility of its occurrence in various types of occupation [5]. In May 2019, the World Health Organization (WHO) recognized burnout as an "occupational syndrome" which will find its place in the 11th Revision of the International Classification of Diseases: ICD-11) [6] in force from 2022. The extensive literature on the subject shows, however, that despite the proven universality of the burnout phenomenon, it is still taboo. Such an attitude is mostly visible, for example, among academic teachers, where, according to research results, knowledge of burnout is most often obtained from the 
Internet or observation of colleagues at work, whereas the employee's formal admission of experiencing burnout is perceived as a sign of weakness [7-9].

The situation looks different in the area of healthcare, where due to the constant emotionally burdening contact with disease and suffering burnout is perceived as something normal. In this sector, nurses are particularly at risk [10-12] due to direct contact with patients and lower social status in relation to the professional group of physicians. The risks in the area of the nursing profession are particularly important in the context of aging societies or of the state of the current pandemic, observed now for almost a year [13]. A lower number of new nurses recruited and the ever higher average age of those who still work are alarming signals of the need to support this professional group. What is interesting is that the research results indicate lower resistance to stress and burnout in younger age groups. For example, in Ireland [14] younger nurses were more likely to report burnout symptoms (68\%) compared to those aged 51 or older (47\%). An Australian study delivered similar results, showing that baby boomers reported lower levels of stress and burnout than generations $X$ and $Y$ [15]. Cross-sectional studies conducted simultaneously in many European countries show a growing crisis in the nursing profession. For example, according to studies conducted in 12 countries, more than one in five nurses (ranging from $11 \%$ in the Netherlands to $56 \%$ in Greece) were dissatisfied with their occupation, and this dissatisfaction was expressed in terms of earnings as well as of educational and development opportunities [16]. The results of this study are worrying, especially when it comes to the percentage of nurses who intend to leave their jobs-this ranged from $19 \%$ in the Netherlands to $49 \%$ in Greece and Finland. According to the results of studies conducted in a group of Swiss nurses and physicians, on average one in 12 healthcare workers demonstrated severe burnout symptoms, and one in six often thought about leaving the profession. Physical, emotional and mental workload and stress at work were strongly and positively associated with the symptoms of burnout and thoughts of leaving the profession [10]. On the other hand, improving the working conditions of nurses is associated with lower rates of occupational burnout, lower intention to leave the current position and less dissatisfaction with work [17].

The importance of the issues of excessive stress and burnout, as well as the extensive literature on the subject, inspired this comparative study in a group of Polish and German nurses. In order to evaluate possible differences and relationships, a proprietary questionnaire was used, in which respondents were asked about specific aspects of employment and occupational burnout. The study was conducted in 2018-2019, and its aim was to evaluate risks in the area of occupational burnout in the context of professional specificity. It was dedicated to the perception of various aspects of one's own work in two countries that differ in terms of the objective level of healthcare and, consequently, working conditions. It is worth noting that the study did not measure the phenomenon of occupational burnout among respondents using such well-known scales as Maslach Burnout Inventory (MBI) [1,4] or the Link Burnout Questionnaire (LBQ) [18], but searched for answers on how nurses perceive their own profession in the context of the risk of burnout, the risk of excessive stress, burnout itself, and possible ways of preventing these problems.

The choice of those two countries was not accidental because over the years many Polish nurses have moved to Germany. According to the study results, the situation of nurses in both countries is perceived as bad, but from the perspective of the situation of Polish nurses the attractiveness of better remuneration or working conditions determines their temporary or permanent departure for work. Studies conducted among German nurses indicate, for example, that in the period 1990-2012 their job satisfaction decreased by an average of $7.5 \%$, while the satisfaction of physicians and other healthcare workers increased by $14.4 \%$ and $1 \%$, respectively [19]. The professional situation of nurses in various environments seems to be characterised by a perceived imbalance between workload, wages and a high risk of burnout symptoms [20]. The degree of control over one's own actions is essential in dealing with stress and burnout, and the nurses who feel little control over their lives are more prone to those unfavourable phenomena [21]. 
Numerous studies conducted among Polish nurses have revealed information about disturbing trends that result in more and more serious shortages of nursing staff, worsening job satisfaction and increasing levels of burnout, which may pose a threat to patient care [22]. It is possible to talk about a crisis, the symptoms of which include the alarmingly high average age of nurses in Poland (52 years), a high percentage of nurses dissatisfied with working conditions [23], a large number of nurses leaving the profession, with a simultaneous increase in the demand for care and nursing services [24]. The research conducted in 2000 and 2014 in the European Union countries showed that Poland ranks sixth from last in terms of the number of nurses per 1000 inhabitants [25]. It is necessary to emphasise that two-thirds of the population of Polish nurses fall into the 41-60 age range, and almost $85 \%$ of them are over 40 [26]. The study results indicate statistically significant relationships between occupational burnout and occupational stress among nurses, as well as differentiation in terms of education, age and seniority [27]. It is also possible to notice that people in management positions perceive their situation in a more positive way [24].

The aim of this study was to examine the differences between countries in the perception of risks in the nursing profession and to assess the relationship between the perception of the specificity of work and factors influencing burnout. Two research questions were formulated to structure the analyses.

The first research question: Are there any differences in the perception of the specificity of work in the nursing profession in Poland and Germany, and are there any differences in this area due to specific professional characteristics such as seniority or decision-making (management vs. non-management position)?

The second research question: Are there any relationships between factors such as the perception of work specificity, the assessment of the risk of excessive stress and the possibilities of preventing burnout?

In order to answer these questions, we used a proprietary questionnaire. Selected questions from the research questionnaire that were used in the article are included in Appendix A, Tables A1 and A2.

\section{Materials and Methods}

\subsection{Data Collection and Research Sample}

The study, which covered nurses working in Polish and German hospitals, was conducted in the period of October 2018-June 2019 using the PAPI method (Paper and Pencil Interview). The staff were employed in hospitals in the Dolnoślaskie and Śląskie Voivodeships in the case of Poland and in the city of Neubrandenburg and its vicinity in the case of Germany. We used a proprietary questionnaire which consisted of 12 closed-ended questions with a choice of answers provided. Depending on the nature of the question, the respondents could choose one answer, multiple answers or evaluate the severity of a given phenomenon. In the latter case, the evaluation was made on a scale from 0 to 10 . In some questions, it was possible to answer, "Difficult to say", coded as missing data. The objective of the study was to collect opinions concerning selected aspects of work in the nursing profession and occupational burnout (level of knowledge, degree of risk and prevention possibilities). The study was anonymous. The results were analysed only in an aggregated form and in separate research groups. The submission of the completed questionnaires by the nurses was considered to be their consent to participate in the study.

In total, 747 complete questionnaires were collected-632 from Poland and 115 from Germany. The characteristics of the respondents according to the features included in the respondent's particulars of the questionnaire form are presented in Table 1. 
Table 1. Research sample—structure according to selected characteristics ( $\mathrm{N}=747)$.

\begin{tabular}{ccc}
\hline Characteristic & Characteristic Category & Percentage of Respondents (\%) \\
\hline \multirow{2}{*}{ Sex } & Female & 91.1 \\
& Male & 8.9 \\
\hline \multirow{2}{*}{ Age } & Less than 25 years & 5.1 \\
& 25-35 years old & 17.9 \\
& 36-45 years old & 19.8 \\
46-55 years old & 38.7 \\
& 56 years and more & 18.5 \\
\hline \multirow{2}{*}{ Current job position } & Non-management position & 16.6 \\
& Management position & 83.4 \\
\hline \multirow{2}{*}{ Seniority } & Less than 5 years & 12.5 \\
& 5-15 years & 17.9 \\
& 16-25 years & 23.1 \\
& More than 25 years & 46.5 \\
\hline
\end{tabular}

It is worth noting that the research samples in both countries differed significantly due to all the characteristics shown in Table 1, apart from current job position, which is mainly the result of greater feminization of the nursing profession in Poland and a higher average age of nursing staff in Poland compared to Germany. In the German sample, 26\% of the respondents were men, whereas in Poland this share equals $6 \%$. The prevailing age category in Poland was 46-55 years old (42\%), while in Germany the distribution of this characteristic was balanced between the first four categories. The different distribution of both samples in the case of age also caused differences in the distribution for the characteristic of seniority. In the German sample, the most common category was seniority of 5-15 years (42\%), whereas for the Polish sample this was 25 (53\%).

\subsection{Methods of Data Analysis}

We performed basic statistical analyses (frequency, mean and standard deviation calculations). In order to find the answer to the first research question, we used a test of equality of distribution in two groups, which was performed with the non-parametric Mann-Whitney $U$ test due to discrete distribution of item responses. Significance of dependency in cross-tables was tested with the asymptotic chi-squared Pearson test of independence. In order to find the answer to the second question, we analysed the correlation matrix between the questions and searched for the possibility of reducing the dimension of the variables on the basis of their relationship in the correlation matrix. The statements describing job characteristics (items) presented in Table A1 and the questionnaire questions shown in Table A2 express a subjective view (or perception) of nurses towards their own work. They are ad hoc scales for measuring latent characteristics. Therefore, in the case of statements describing the job characteristics, multivariate analyses [28] were carried out based on the correlation matrix between items: reliability analysis with Cronbach's alpha coefficient, exploratory factor analysis (EFA) with the principal components method and varimax rotation and confirmatory factor analysis (CFA) with the maximum likelihood estimation method. As for performing statistical analyses, we used the statistical software Statistica 12.5 [29] and IBM SPSS 26 [30].

\section{Results}

\subsection{The Specificity of the Nursing Profession}

The perception of the specificity of work in the nursing profession was analysed on the basis of 16 statements (see Table A1 in the Appendix A). The respondents evaluated to what extent a given statement accurately described their work on a scale from 0 to 10 , where 0 meant that it did not fit the nature of the work, and 10 that it definitely did. These statements were positive as well as negative. The highest mean value for the entire research sample was noted for the evaluation of work as involving contact with 
others (9.04). At the same time, for this category there was the smallest differentiation of opinions (standard deviation at the level of 2.10). For the next three statements, the average value exceeded 7 . These concerned good fit to the work performed (7.77), too much bureaucracy (7.30) and maintaining work-life balance (7.04). The lowest number of respondents agreed with the statements relating to the willingness to change jobs, stressful relationships with co-workers and superiors. In each of these cases, the mean evaluation was below 4. Relatively significant differentiation was noted in the evaluation of the willingness to change job and take some rest from work (standard deviation at the level of 3.31 and 3.30, respectively). Apart from stating that the work involved contact with other people, a lot of respondents agreed with the statement concerning suitability for the job that one does (standard deviation at the level of 2.45). The significance of differentiation in the opinions of respondents characterised by different features was determined on the basis of the Mann-Whitney U test. We took into consideration characteristics such as country, position held and seniority. The results are presented in Table 2. It should be emphasised that these three binary grouping characteristics are not independent of each other, and that a significant relationship between seniority and the position held was expected $(p<0.001)$. There was no significant relationship between country and the position $(p=0.221)$, but there was a significant relationship between country and seniority $(p<0.001)$-in many cases Polish nurses have more than 15 years of experience.

Table 2. Diversification of opinions concerning work in the nursing profession due to selected characteristics of the respondents.

\begin{tabular}{|c|c|c|c|c|c|c|c|c|c|}
\hline \multirow{3}{*}{ Item } & \multicolumn{3}{|c|}{ Country } & \multicolumn{3}{|c|}{ Current Job Position } & \multicolumn{3}{|c|}{ Seniority } \\
\hline & \multicolumn{2}{|c|}{ Mean \pm St. Dev. } & \multirow{2}{*}{$p$-Value } & \multicolumn{2}{|c|}{ Mean \pm St. Dev. } & \multirow{2}{*}{$p$-Value } & \multicolumn{2}{|c|}{ Mean \pm St. Dev. } & \multirow{2}{*}{$p$-Value } \\
\hline & DE & PL & & NMP & MP & & Up to 15 Years & Over 15 Years & \\
\hline $1 \mathrm{a}$ & $5.64 \pm 2.74$ & $6.58 \pm 2.93$ & $* * *$ & $6.38 \pm 2.94$ & $6.56 \pm 2.81$ & ns & $6.06 \pm 2.76$ & $6.60 \pm 2.98$ & $* *$ \\
\hline $1 b$ & $4.60 \pm 3.29$ & $6.23 \pm 3.21$ & $* * *$ & $6.23 \pm 3.21$ & $4.69 \pm 3.25$ & $* * *$ & $5.63 \pm 3.18$ & $6.12 \pm 3.30$ & $*$ \\
\hline 1c & $5.12 \pm 2.72$ & $5.61 \pm 2.73$ & $\ddagger$ & $5.52 \pm 2.72$ & $5.75 \pm 2.77$ & ns & $5.42 \pm 2.66$ & $5.60 \pm 2.75$ & ns \\
\hline $1 d$ & $8.25 \pm 3.02$ & $9.19 \pm 1.85$ & * & $9.11 \pm 1.99$ & $8.84 \pm 2.40$ & ns & $9.00 \pm 2.08$ & $9.07 \pm 2.08$ & ns \\
\hline $1 \mathrm{e}$ & $3.97 \pm 2.98$ & $3.69 \pm 3.31$ & ns & $3.75 \pm 3.28$ & $3.88 \pm 3.17$ & ns & $3.76 \pm 3.13$ & $3.71 \pm 3.32$ & ns \\
\hline 1f & $4.19 \pm 2.64$ & $3.62 \pm 2.98$ & $*$ & $3.60 \pm 2.89$ & $4.41 \pm 3.05$ & $*$ & $3.72 \pm 2.72$ & $3.70 \pm 3.02$ & ns \\
\hline $1 \mathrm{~g}$ & $5.78 \pm 3.16$ & $7.58 \pm 2.91$ & $* * *$ & $7.30 \pm 3.02$ & $7.42 \pm 2.92$ & ns & $6.94 \pm 2.87$ & $7.44 \pm 3.06$ & $* *$ \\
\hline $1 \mathrm{~h}$ & $5.90 \pm 2.85$ & $5.86 \pm 2.92$ & ns & $5.77 \pm 2.92$ & $6.36 \pm 2.86$ & $*$ & $5.51 \pm 2.75$ & $6.02 \pm 2.97$ & $*$ \\
\hline $1 \mathrm{i}$ & $4.11 \pm 2.97$ & $4.34 \pm 3.27$ & ns & $4.15 \pm 3.15$ & $4.82 \pm 3.37$ & $\ddagger$ & $4.00 \pm 2.93$ & $4.42 \pm 3.33$ & ns \\
\hline $1 \mathrm{j}$ & $3.80 \pm 2.31$ & $4.77 \pm 2.76$ & $* * *$ & $4.59 \pm 2.72$ & $4.75 \pm 2.63$ & $\ddagger$ & $4.18 \pm 2.52$ & $4.83 \pm 2.78$ & $* *$ \\
\hline $1 \mathrm{k}$ & $6.90 \pm 2.97$ & $7.93 \pm 2.31$ & $* * *$ & $7.76 \pm 2.46$ & $7.86 \pm 2.36$ & ns & $7.44 \pm 2.53$ & $7.94 \pm 2.41$ & $* *$ \\
\hline 11 & $6.37 \pm 2.94$ & $7.17 \pm 2.73$ & $* *$ & $7.12 \pm 2.76$ & $6.54 \pm 2.82$ & $*$ & $6.89 \pm 2.83$ & $7.11 \pm 2.76$ & ns \\
\hline $1 \mathrm{~m}$ & $5.97 \pm 2.70$ & $7.09 \pm 2.49$ & $* * *$ & $6.88 \pm 2.53$ & $7.12 \pm 2.61$ & ns & $6.80 \pm 2.45$ & $6.98 \pm 2.62$ & ns \\
\hline $1 n$ & $3.57 \pm 3.29$ & $3.22 \pm 3.31$ & ns & $3.35 \pm 3.33$ & $2.71 \pm 3.01$ & $\ddagger$ & $3.48 \pm 3.07$ & $3.15 \pm 3.41$ & $\ddagger$ \\
\hline 1o & $4.68 \pm 3.09$ & $6.20 \pm 3.28$ & $* * *$ & $6.11 \pm 3.29$ & $5.27 \pm 3.12$ & $* *$ & $5.60 \pm 3.31$ & $6.11 \pm 3.29$ & * \\
\hline $1 p$ & $5.30 \pm 2.98$ & $6.74 \pm 2.68$ & $* * *$ & $6.41 \pm 2.79$ & $6.94 \pm 2.64$ & $\ddagger$ & $6.29 \pm 2.68$ & $6.62 \pm 2.82$ & $\ddagger$ \\
\hline
\end{tabular}

${ }^{* * *} p<0.001,{ }^{* *} 0.001 \leq p<0.01,{ }^{*} 0.01 \leq p<0.05, \ddagger 0.05 \leq p<0.1$, ns—non-significant; DE-Germany, PL—Poland, NMP—Non-management position, MP-Management position.

The greatest differences in the perception of the specificity of work in the nursing profession were observed in the case of the country characteristic. Significant differences between the opinions of Polish and German nurses occurred for 11 of 16 statements, and for 8 of these the $p$-value from the Mann-Whitney $\mathrm{U}$ test was below 0.001. Taking into consideration the undesirable phenomena, Polish nurses, more often than German ones, experience too much bureaucracy and high physical workload, and also dream more about taking some rest from work. At the same time, they more often agreed with the opinion that they have an influence on the way they perform their work, that they are satisfied with it and that they are suited to what they do. As for seniority, significant differences occurred in seven cases. However, these were smaller than in the case of comparisons between countries. Respondents with more than 15 years of work experience, more often than those working for a shorter time in the profession, noticed too much bureaucracy, little success at work and accompanying excessive stress, as well as the need to adapt to a large number of 
changes. They feel more tired, which resulted in higher average evaluations for statements regarding excessive physical workload and desire to take some rest from work. More often than people with 15 years of experience, they also agree that they are suited to the job they do. The fewest significant differences (five cases) appeared in the case of evaluations expressed by people holding management and non-management positions. The biggest difference was noted for the statement concerning high physical workload, which is less of a problem for people in management positions, who also less often thought about taking some rest from work. On the other hand, they more often assessed relationships with co-workers as stressful, and they also have a greater problem with maintaining proper work-life balance and adapting to a larger number of changes.

An analogous analysis was carried out for the remaining six questions from the questionnaire included in the article. The numerical results are presented in Table 3.

Table 3. Differentiation of opinions in the area of occupational burnout and accompanying phenomena due to selected characteristics of the respondents.

\begin{tabular}{|c|c|c|c|c|c|c|c|c|c|}
\hline \multirow{3}{*}{ Question } & \multicolumn{3}{|c|}{ Country } & \multicolumn{3}{|c|}{ Current Job Position } & \multicolumn{3}{|c|}{ Seniority } \\
\hline & \multicolumn{2}{|c|}{ Mean \pm St. Dev. } & \multirow{2}{*}{$p$-Value } & \multicolumn{2}{|c|}{ Mean \pm St. Dev. } & \multirow{2}{*}{$p$-Value } & \multicolumn{2}{|c|}{ Mean \pm St. Dev. } & \multirow{2}{*}{$p$-Value } \\
\hline & $\mathrm{DE}$ & PL & & NMP & MP & & Up to 15 years & Over 15 years & \\
\hline 2 & $2.71 \pm 0.94$ & $2.70 \pm 0.93$ & ns & $2.74 \pm 0.91$ & $2.48 \pm 0.95$ & $* *$ & $2.71 \pm 0.84$ & $2.69 \pm 0.96$ & ns \\
\hline 3 & $1.54 \pm 0.65$ & $1.69 \pm 0.61$ & $* *$ & $1.69 \pm 0.62$ & $1.59 \pm 0.63$ & ns & $1.62 \pm 0.66$ & $1.69 \pm 0.60$ & $\ddagger$ \\
\hline 4 & $5.73 \pm 2.23$ & $7.49 \pm 2.18$ & $* * *$ & $7.15 \pm 2.29$ & $7.49 \pm 2.17$ & ns & $6.63 \pm 2.21$ & $7.43 \pm 2.25$ & $* * *$ \\
\hline 7 & $6.75 \pm 2.24$ & $7.97 \pm 2.40$ & $* * *$ & $7.84 \pm 2.41$ & $7.67 \pm 2.39$ & ns & $7.58 \pm 2.22$ & $7.87 \pm 2.50$ & * \\
\hline 8 & $6.39 \pm 2.57$ & $6.10 \pm 2.84$ & ns & $6.04 \pm 2.84$ & $6.50 \pm 2.63$ & ns & $5.95 \pm 2.75$ & $6.23 \pm 2.82$ & ns \\
\hline 11 & $1.94 \pm 0.83$ & $2.29 \pm 0.92$ & $* * *$ & $2.30 \pm 0.93$ & $1.91 \pm 0.77$ & $* * *$ & $2.06 \pm 0.84$ & $2.31 \pm 0.93$ & $* *$ \\
\hline
\end{tabular}

${ }^{* * *} p<0.001,{ }^{* *} 0.001 \leq p<0.01,{ }^{*} 0.01 \leq p<0.05,{ }^{\ddagger} 0.05 \leq p<0.1$, ns—-non-significant; DE—Germany, PL—Poland, NMP—Non-management position, MP-Management position.

We have not found any significant differences in the assessment of the feeling of reluctance to go to work between respondents from Germany and Poland and between people with different levels of seniority. A significant difference was noted only for people in non-management and management positions-reluctance was more often felt by people who did not perform managerial functions. Polish nurses, less frequently than German nurses, declared having regular activities apart from their work and household duties, which they perform for themselves, for their own pleasure or development. The other two categories did not differentiate this phenomenon in a significant manner. Polish respondents evaluated their knowledge of occupational burnout and the ability to recognise its symptoms much more highly than German respondents. The same happened for the group of people with more than 15 years of work experience in relation to people working in the profession for a shorter period of time. The position in the workplace did not have any influence on self-assessment of knowledge of the phenomenon of occupational burnout. This is perceived as a serious problem in the healthcare sector, with the mean for the Polish sample being significantly higher than for the German. People with longer work experience seem to notice a greater risk. It is worth noting that none of the three analysed categories appeared to differentiate in the case of evaluation of the difficulty in admitting occupational burnout in the workplace. However, all differentiated when evaluating the possibilities of occupational burnout prevention in healthcare. More sceptical in this respect were respondents from Poland, people working in non-management positions and those with longer work experience.

\subsection{Factor and Reliability Analysis for Groups of Characteristics Typical of the Nursing Profession}

Exploratory factor analysis of question 1 items is presented in Table 4. Four eigenvalues are greater than one, so a four factor structure is estimated. Loadings greater than 0.45 are marked with bold red font.

The analysis of the content of the groups of questions assigned to the various factors shows that they came together because of similar content. The names that can be assigned 
to the four identified factors are as follows: factor 1-workload, factor 2-job satisfaction, factor 3-stressful atmosphere in the organisation, factor 4-feeling of control over one's own work.

Table 4. Factor loadings of exploratory factor analysis (EFA) with principal components method and varimax rotation.

\begin{tabular}{|c|c|c|c|c|}
\hline Item & Factor 1 & Factor 2 & Factor 3 & Factor 4 \\
\hline $1 \mathrm{a}$ & 0.664 & 0.002 & 0.158 & 0.238 \\
\hline $1 b$ & 0.679 & -0.081 & -0.002 & 0.23 \\
\hline $1 c$ & 0.116 & 0.095 & 0.079 & 0.791 \\
\hline $1 d$ & 0.515 & 0.408 & 0.031 & 0.153 \\
\hline $1 \mathrm{e}$ & 0.244 & -0.226 & 0.681 & 0.005 \\
\hline 1f & 0.139 & -0.227 & 0.707 & 0.208 \\
\hline $1 \mathrm{~g}$ & 0.657 & 0.162 & 0.244 & -0.257 \\
\hline $1 \mathrm{~h}$ & 0.545 & 0.02 & 0.393 & -0.162 \\
\hline $1 \mathrm{i}$ & -0.24 & 0.283 & 0.469 & -0.04 \\
\hline $1 j$ & 0.184 & 0.079 & 0.57 & -0.023 \\
\hline $1 \mathrm{k}$ & 0.195 & 0.769 & 0.05 & 0.057 \\
\hline 11 & 0.05 & 0.653 & -0.029 & 0.143 \\
\hline $1 \mathrm{~m}$ & -0.111 & 0.79 & -0.028 & 0.191 \\
\hline $1 \mathrm{n}$ & 0.332 & -0.594 & 0.137 & 0.087 \\
\hline 10 & 0.62 & -0.381 & 0.066 & 0.016 \\
\hline $1 p$ & 0.059 & 0.415 & -0.022 & 0.586 \\
\hline
\end{tabular}

In order to further investigate the measurement properties, the values of the Cronbach's alpha reliability coefficient were calculated for sub-scales developed from marked items in Table 4. Cronbach's alpha value for Factor 1 scale (1a, 1b, 1g, 1h, 1o) equals 0.72; for Factor 2 scale $(1 \mathrm{k}-1 \mathrm{~m}, 1 \mathrm{n}$ recoded) 0.71 ; Factor 3 scale is almost sufficiently reliable only for the 1e-1f subscale (alpha equals 0.67); Factor 4 scale is not reliable (alpha equals 0.44 ). Only reliable Factors 1-3 scales were used in the next analyses.

A three factor structure was tested with the confirmatory factor analysis model (maximum likelihood estimation method) for the set question 1 items without the items (1c, $1 \mathrm{i}$, $1 \mathrm{p})$, which poorly correlated with the rest of items. The results of this analysis are shown in Table 5.

Table 5. Three-factor confirmatory factor analysis (CFA) model: parameter estimates and significance.

\begin{tabular}{ccc}
\hline Latent Variable & Item & Standardized Factor Loading or Correlation \\
\hline & $1 \mathrm{a}$ & $0.663^{* * *}$ \\
Factor 1-workload & $1 \mathrm{~b}$ & $0.604^{* * *}$ \\
& $1 \mathrm{~g}$ & $0.540^{* * *}$ \\
& $1 \mathrm{~h}$ & $0.559^{* * *}$ \\
& $1 \mathrm{o}$ & $0.525^{* * *}$ \\
\hline Factor 2-job satisfaction & $1 \mathrm{k}$ & $0.655^{* * *}$ \\
& $1 \mathrm{~m}$ & $0.542^{* * *}$ \\
& $1 \mathrm{n}$ & $0.856^{* * *}$ \\
\hline Factor 3-stressful & $1 \mathrm{e}$ & $-0.500^{* * *}$ \\
atmosphere in the & $1 \mathrm{f}$ & $0.731^{* * *}$ \\
organisation & $1 \mathrm{j}$ & $0.680^{* * *}$ \\
& $\mathrm{r}(1,2)$ & $0.338^{* * *}$ \\
\hline & $\mathrm{r}(1,3)$ & $-0.131^{* * *}$ \\
Correlations between factors & $\mathrm{r}(2,3)$ & $0.575^{* * *}$ \\
& & $-0.240^{* * *}$ \\
\hline
\end{tabular}

$\overline{* * *} p<0.001, * * p<0.01$.

The low loading at $1 \mathrm{j}$ is an argument for not including this variable in the measurement of factor 3 . The remaining factor loadings are at least 0.5 in relation to the absolute value. 
All the correlations between the factors are significant, with factor 1 relating to workload and factor 3 relating to the stressful atmosphere in the organisation as the most strongly correlated. Factor 2 concerning job satisfaction is negatively correlated with the others, which may indicate that satisfaction is as an individual feature of the respondents, less dependent on the external situation at work.

The evaluation of the quality of the CFA model performed with the most commonly used indicators [31] is presented in Table 6.

Table 6. Characteristics and goodness-of-fit statistics for the three-factor CFA model.

\begin{tabular}{cc}
\hline Measure & Score \\
\hline Chi square & 406.03 \\
degrees of freedom (df) & 51 \\
Chi square/df (minimum discrepancy) & 7.96 \\
SRMR (minimum discrepancy) & 0.092 \\
RMSEA (root mean square error of approximation) & 0.098 \\
GFI (goodness of fit index) & 0.915 \\
AGFI (adjusted goodness of fit index) & 0.870 \\
CFI (comparative fit index) & 0.814 \\
NFI (normed fit index) & 0.794
\end{tabular}

Comparing the obtained values from Table 6 to strict requirements given by Schreiber et al. [32], the CFA model cannot be considered as the final measurement model. Most wellmatched to the data. However, these indicators show that, at the initial stage of creating such a model, a fairly good fit is achieved that could be the basis for further improvements to the measurement model. Nevertheless, due to the lack of a very good fit of the model to the data, it is reasonable to analyse both individual items, which was done point 3.1, as well as selected factors that allow us to reduce the dimension of the variables describing the work of nurses.

Finally, to recapitulate the above analysis, differences in mean values of derived reliably measured three factors are shown in Table 7 with the $p$-value from the MannWhitney U test to compare country, current job position and seniority categories. Polish nurses feel greater workload (Factor 1), but also greater job satisfaction (Factor 2) than German nurses. However, the difference in stressful atmosphere in the organisation (Factor 3) between countries is only on the borderline of significance (a greater feeling of stressful atmosphere among German nurses). No significant differences are observed between non-management and management positions. Nurses with seniority over 15 years feel significantly greater workload, but also greater job satisfaction (on the borderline of significance).

Table 7. Differentiation of opinions concerning work in the nursing profession due to selected factors.

\begin{tabular}{|c|c|c|c|c|c|c|c|c|c|}
\hline \multirow{3}{*}{ Factor } & \multicolumn{3}{|c|}{ Country } & \multicolumn{3}{|c|}{ Current Job Position } & \multicolumn{3}{|c|}{ Seniority } \\
\hline & \multicolumn{2}{|c|}{ Mean \pm St. Dev. } & \multirow{2}{*}{$p$-Value } & \multicolumn{2}{|c|}{ Mean \pm St. Dev. } & \multirow{2}{*}{$p$-Value } & \multicolumn{2}{|c|}{ Mean \pm St. Dev. } & \multirow{2}{*}{$p$-Value } \\
\hline & $\mathrm{DE}$ & PL & & NMP & MP & & Up to 15 Years & Over 15 Years & \\
\hline 1 & $5.32 \pm 2.11$ & $6.49 \pm 2.08$ & $* * *$ & $6.36 \pm 2.13$ & $6.09 \pm 1.99$ & ns & $5.95 \pm 2.02$ & $6.46 \pm 2.14$ & $* * *$ \\
\hline 2 & $6.42 \pm 2.19$ & $7.25 \pm 1.99$ & $* * *$ & $7.11 \pm 2.05$ & $7.22 \pm 1.94$ & ns & $6.93 \pm 2.08$ & $7.22 \pm 2.03$ & $\ddagger$ \\
\hline 3 & $4.08 \pm 2.43$ & $3.66 \pm 2.75$ & $\ddagger$ & $3.68 \pm 2.67$ & $4.17 \pm 2.79$ & ns & $3.74 \pm 2.57$ & $3.71 \pm 2.76$ & ns \\
\hline
\end{tabular}

${ }^{* * *} p<0.001,{ }^{* *} 0.001 \leq p<0.01,{ }^{*} 0.01 \leq p<0.05,{ }^{\ddagger} 0.05 \leq p<0.1$, ns—non-significant; DE—Germany, PL—Poland, NMP—Non-management position, MP-Management position.

3.3. Relationship between the Factors Describing the Specificity of the Nursing Profession and the Issues of Occupational Burnout

The analysis of correlation between variables was performed using both the Pearson linear correlation coefficient and the Spearman's rank correlation coefficient. Since the conclusions from the analysis of both types of correlations were identical, Table 8 presents the linear correlation matrix. A "Difficult to say answer" option, allowed for some questions, 
was always coded as missing data, a pairwise deletion of missing data was used, and a count of $\mathrm{N}$ was given for each value of the correlation coefficient.

Table 8. Pearson's linear correlations between the factors describing the specificity of the nursing profession and the issues of occupational burnout.

\begin{tabular}{|c|c|c|c|}
\hline Question & Factor 1 & Factor 2 & Factor 3 \\
\hline \multirow{3}{*}{2} & 0.4484 & -0.487 & 0.2873 \\
\hline & $\mathrm{N}=743$ & $\mathrm{~N}=741$ & $\mathrm{~N}=738$ \\
\hline & $* * *$ & $* * *$ & $* * *$ \\
\hline \multirow{3}{*}{3} & 0.1347 & -0.1415 & 0.0523 \\
\hline & $\mathrm{N}=737$ & $\mathrm{~N}=735$ & $\mathrm{~N}=732$ \\
\hline & $* * *$ & $* * *$ & ns \\
\hline \multirow{3}{*}{4} & 0.0978 & 0.1939 & -0.0149 \\
\hline & $\mathrm{N}=727$ & $\mathrm{~N}=725$ & $\mathrm{~N}=723$ \\
\hline & $* *$ & $* * *$ & ns \\
\hline \multirow{3}{*}{7} & 0.297 & -0.0995 & 0.1666 \\
\hline & $\mathrm{N}=691$ & $\mathrm{~N}=689$ & $\mathrm{~N}=687$ \\
\hline & $* * *$ & $* *$ & $* * *$ \\
\hline \multirow{3}{*}{8} & 0.0553 & 0.0743 & 0.0794 \\
\hline & $\mathrm{N}=658$ & $\mathrm{~N}=657$ & $\mathrm{~N}=655$ \\
\hline & ns & ns & * \\
\hline \multirow{3}{*}{11} & 0.1602 & -0.1221 & 0.132 \\
\hline & $\mathrm{N}=581$ & $\mathrm{~N}=581$ & $\mathrm{~N}=579$ \\
\hline & $* * *$ & $* *$ & ** \\
\hline
\end{tabular}

Most of the observed values are significantly different from zero, but these are rather weak correlations. The strongest relationships appeared between reluctance to go to work (question 2) and Factor 1 (workload) - a positive correlation-and Factor 2 (job satisfaction) - a negative correlation, which is understandable. There is also a significant positive correlation between reluctance to go to work and stressful atmosphere in the organisation. Much lower values of the correlation coefficient occur for participation in after-work activities (question 3) - due to the coding of this variable, we interpret that the perception of work as burdening (Factor 1) is associated with less frequent participation, whereas job satisfaction (Factor 2) is associated with more frequent participation in this type of activity. The declared level of knowledge and recognition of burnout (question 4) is mainly related to higher job satisfaction, but also significantly to the perception of work as more burdening. The feeling of a general risk of burnout in the healthcare sector (question 7) is most strongly associated with the perceived workload, then with the stressful atmosphere in the organisation, and finally with lower job satisfaction. The only significantly different from zero correlation in Table 8 for the ease of admitting burnout (question 8) is observed for stressful atmosphere in the organisation resulting from the relationship with superiors and co-workers, which, however, is a weak correlation. A greater perception of burnout preventive measures (question 11) is associated with a lower perceived workload and less stressful atmosphere in the organisation, as well as higher job satisfaction.

\section{Discussion}

Referring to the research questions it is possible to state that the obtained results of the study carried out on the basis of the proprietary questionnaire showed differences in the perception of the specificity of work in the nursing profession in Poland and in Germany in relation to various aspects relating to the risk of occupational burnout. They also revealed differences in this area due to professional characteristics such as seniority or decision-making in the position held, understood as a management vs. non-management 
positions. The reasons for the observed significant differences may be objective financial conditions (higher remuneration in Germany and in management positions), or cultural values influencing the status of the nurse in society and the situation in the sector (very high feminisation of the profession in Poland, too few new nurses recruited resulting in aging staff). Another aspect which may also influence perception is that of selection, which means that employees suffering from burnout have less chance of longer seniority and what usually follows - taking a management position. In order to reduce the risk of occupational burnout, individual predispositions of the employee should make it possible to meet the requirements of the profession and the stress associated with it. Bearing in mind that it is not always possible to help all sick patients and enjoying the fact of helping other people, should bring satisfaction within this profession even though one's financial expectations are not fully met. Items describing own work are grouped into 4 factors reflecting latent variables, three of which can be reliably measured-workload, job satisfaction and stressful atmosphere at work. The analysis of the relationship with the remaining questions showed that the perception of one's job as being burdensome is most strongly associated with the reluctance to go to work, which may be a symptom of burnout. There are also quite strong relationships between workload and the perception of a higher risk of burnout in this sector, as well as poorer possibilities of preventing it. On the other hand, job satisfaction is most strongly associated with the willingness to go to work, and also with the belief that one understands the phenomenon of occupational burnout and is able to recognise it in oneself and in colleagues. A stressful atmosphere at work is most strongly associated with reluctance to go to work, as well as a feeling of a higher risk of burnout.

The obtained results confirmed those achieved by other research teams conducting studies on occupational stress or burnout symptoms in nurses. First of all, they confirmed the difficult situation in the nursing profession in both countries-the exhaustion of the staff and the lack of effective organisational solutions that could improve the situation in the future. As for the research mentioned in the introduction [16], as many as $44 \%$ of nurses from Poland and 36\% from Germany indicated their intention to change their current job. The obtained results are consistent with the results of research conducted in a group of German nurses, which indicated the need to introduce preventive and intervention strategies that would focus both on the individual and on working conditions [33].

An interesting aspect of the discussion on risks in the nursing profession is the result of studies on the relationship between the sense of coherence (and its components) and patterns of professional behaviour in nurses [34]. According to this, the sense of coherence can be treated as specific personal potential for nurses, which may be of significant importance in the process of coping with stress and symptoms of burnout. Therefore, training for this professional group in soft skills, including the issues of coping with stress at work, is very important. Another way to improve the situation is to provide nurses with real-time feedback that can mitigate the negative influence of physical and mental stress on their well-being [35]. The results of research conducted in a group of nurses from Finland and the Netherlands made it possible to identify three good practices [36]: resource adequacy, management support and ensuring proper quality of care through relationships based on cooperation. Positive evaluations of the adequacy of resources and support from management were positively correlated with the nurses' assessment of the quality of care and positive feelings about work, and negatively correlated with intentions to leave the job, the organisation or even the profession.

Referring to the skills of working under time pressure required in the nursing profession, they seem to be particularly important in the context of emergency situations. An interesting voice in the discussion are the results of research conducted on Polish and Saudi Arabian nurses, where it was found that work experience, workplace preparedness, training and experience in disaster response are key factors for the effectiveness of actions undertaken in such conditions [37,38]. In conclusion, it is worth emphasizing that the research was conducted in 2018 and 2019, i.e., in the so-called "normal", non-pandemic conditions. The COVID-19 turmoil, which has placed a huge strain on healthcare pro- 
fessionals around the world, has also left its mark on the issues raised in the article. It seems that the repetition of this research after the pandemic period may provide additional information worth considering when developing prevention programs against burnout in the nursing profession.

When referring to the future of the nursing profession, the key task seems to be the improvement of the prestige of this occupation and working conditions. According to the results of the research conducted among Polish nursing students, the decision to choose the profession results mainly from practical issues related to the possibility of employment and helping others, but also from the belief that the prestige of the profession and working conditions can be improved [39]. Feeling pride in being a nurse and searching for strategies that could support nurses in their daily work have been mentioned in the results of the studies conducted among Belgian nurses [40].

\section{Limitations}

The results should be interpreted with a certain degree of caution due to the limitations of the research sample-it was not selected randomly, although we made efforts to make it representative for the analysed populations. The compared samples from two countries are not of the same size. They are characterized by a disproportion because much more data were collected in Poland than in Germany. The analysis of the relationships between characteristics and country and seniority can be biased with an undesirable relationship between them-Polish nurses have significantly longer professional experience, and therefore, they are also older.

Although it is possible to hold some reservations about the statistical correctness of the research sample, the implementation of primary research dedicated to risks in the nursing profession on research samples from two countries differing in system solutions offered numerous interesting results. The presented outcomes may encourage thinking about the effectiveness of the adopted solutions and their influence on the feeling of facing excessive stress and occupational burnout in nurses. It seems justified to conduct the research one more time on the basis of the same or similar questionnaire, especially after the pandemic period, when the situation of nurses and certainty of employment have significantly deteriorated. In the view of declining interest in nursing studies on the part of young people, many nurses retiring from work and an increasingly older population of this professional group, it seems crucial to take a closer look at how nurses perceive their occupation in the context of potential risks, find effective solutions preventing them from giving up their jobs and make the profession both more prestigious and more attractive.

\section{Conclusions}

According to the conducted research, the risk of excessive stress and burnout among nurses is noticed in both countries, but for different reasons. This is especially proven by the fact that differences in the perception of the profession among nurses from Poland and Germany occurred for 11 out of 16 statements, and for eight of these the p-value from the Mann-Whitney $U$ test was below 0.001. It seems that Polish nurses are much more stressed and physically exhausted. This is probably due to the quite common phenomenon of working in several places, in the case of which the number of hours spent at work equals two full-time positions (the effect of very low salaries). Nevertheless, bureaucracy and lack of success or of an effective promotion path seem to be more distressing. Nurses would like to take some rest, but on the other hand they feel that they are suited to the work they do and have a greater sense of influence on how they perform it. They are also more satisfied with their work. German nurses, on the other hand, complain to a greater extent about stressful relationships with their superiors and colleagues, and they would also be more willing to change their job. In relation to the remaining questions, it is worth noting that nurses from Germany more often declared doing something for a treat, that is, having a hobby or performing activities which are not connected with their professional or household duties, which are performed only for pleasure or development, 
and which are often considered an effective form of prevention of occupational burnout. The research results also showed a worse evaluation of the situation by Polish nurses in the context of burnout as a serious problem for the healthcare sector and their greater scepticism concerning possible preventive measures in this regard.

Author Contributions: Conceptualization, U.Z., D.K.-C. and C.K.; methodology, U.Z., D.K.-C. and C.K.; formal analysis, U.Z. and C.K.; investigation, D.K.-C.; resources, U.Z., D.K.-C. and C.K.; data curation, U.Z. and C.K.; writing - original draft preparation, U.Z., D.K.-C. and C.K.; writing-review and editing, U.Z., D.K.-C. and C.K.; visualization, C.K.; supervision, D.K.-C.; project administration, U.Z.; funding acquisition, D.K.-C. and U.Z. All authors have read and agreed to the published version of the manuscript.

Funding: The project is financed by the Ministry of Science and Higher Education in Poland under the programme "Regional Initiative of Excellence" 2019-2022 project number 015/RID/2018/19 total funding amount 10,721,040.00 PLN.

Institutional Review Board Statement: Ethical review and approval were waived for this study, because the survey did not concern any critical ethical issues survey: neither respondent health measurement nor health intervention in the research process. The whole survey questionnaire in English, German or Polish language is available upon request from the corresponding author.

Informed Consent Statement: Respondent consent was waived, because no experimental manipulation was used during the research. Respondents were well informed about participation in the study on social issues of description of situation in own work and the whole industry and finally they voluntarily decided to take part in the survey. They were assured that the interview is completely confidential and will be conducted in accordance with ethical standards in opinion research.

Data Availability Statement: The dataset presented in the study is available upon request from the corresponding author.

Acknowledgments: The authors would like to thank Stefan Schmidt for conducting the study among German hospital nurses and Agnieszka Pietrus-Rajman for preparing the questionnaire in German.

Conflicts of Interest: The authors declare no conflict of interest.

\section{Appendix A}

Table A1. General questions about work: Please assess to what extent each of the questions describes your current job.

\begin{tabular}{|c|c|c|}
\hline No. & Item & Response Variants and Coding \\
\hline $1 \mathrm{a}$ & High emotional stress & \multirow{16}{*}{$\begin{array}{l}\text { The scale of } 0 \text { to } 10 \text {, where } 0 \text { - definitely } \\
\text { inadequate, } 10 \text {-definitely adequate }\end{array}$} \\
\hline $1 b$ & Great physical strain & \\
\hline 1c & I am mostly responsible for my work results & \\
\hline $1 \mathrm{~d}$ & My work involves contact with others & \\
\hline $1 \mathrm{e}$ & A stressful relationship with a supervisor & \\
\hline 1f & Stressful relationships with coworkers & \\
\hline $1 \mathrm{~g}$ & Too much bureaucracy & \\
\hline $1 \mathrm{~h}$ & A dynamic environment/a necessity to adapt & \\
\hline $1 \mathrm{i}$ & An adequate remuneration for work & \\
\hline $1 \mathrm{j}$ & Little success at work & \\
\hline $1 \mathrm{k}$ & I feel that my work suits me & \\
\hline 11 & I maintain a work-life balance & \\
\hline $1 \mathrm{~m}$ & I am satisfied with my work & \\
\hline $1 \mathrm{n}$ & I would like to change my job & \\
\hline 1o & I wish I could take some time off work & \\
\hline $1 \mathrm{p}$ & I can influence the way I do my work & \\
\hline
\end{tabular}


Table A2. The remaining analysed questions.

\begin{tabular}{|c|c|c|c|}
\hline No & Question & Response Variants and Coding & \\
\hline \multirow{5}{*}{2} & \multirow{5}{*}{$\begin{array}{l}\text { How often do you feel like not going to work, } \\
\text { when thinking about your current job? }\end{array}$} & Never & 1 \\
\hline & & Very rarely & 2 \\
\hline & & Occasionally & 3 \\
\hline & & Often & 4 \\
\hline & & Constantly & 5 \\
\hline \multirow{3}{*}{3} & \multirow{3}{*}{$\begin{array}{l}\text { Do you take part in any leisure or personal } \\
\text { development activities, other than your } \\
\text { professional and domestic duties? }\end{array}$} & Yes, regularly & 1 \\
\hline & & Yes, although sporadically & 2 \\
\hline & & No & 3 \\
\hline
\end{tabular}

Please think about "burnout" for a moment.

How would you describe your level of understanding of this phenomenon? Please describe to what extent you agree with the following statements.

$4^{1} \quad$ a. I have sufficient understanding of burnout

b. I could recognize the symptoms of burnout if they affect me personally

c. I am able to tell whether somebody else shows the symptoms of burnout

\begin{tabular}{|c|c|c|}
\hline 7 & $\begin{array}{l}\text { When thinking about your industry, could you } \\
\text { describe how serious the problem of burnout is? }\end{array}$ & $\begin{array}{c}\text { The scale of } 0 \text { to } 10 \text { where } 0 \text { - it is not a problem, } 10 \text { - it is a } \\
\text { serious problem }\end{array}$ \\
\hline 8 & $\begin{array}{l}\text { When thinking about your industry-how easy } \\
\text { would it be to admit to being burn-out at a } \\
\text { workplace if somebody's position were similar to } \\
\text { yours? }\end{array}$ & The scale of 0 to 10 where 0 -very easy, 10 -very difficult \\
\hline \multirow{5}{*}{11} & \multirow{5}{*}{$\begin{array}{l}\text { Do you think the prevention of burnout is } \\
\text { possible in your industries? }\end{array}$} & Definitely yes \\
\hline & & Rather yes \\
\hline & & Rather no \\
\hline & & Definitely no \\
\hline & & Difficult to say \\
\hline
\end{tabular}

${ }^{1}$ In the case of question 4 , we combined responses to 3 statements $(a, b, c)$ due to their strong correlation and analysed them together as the mean of the responses to the 3 statements given with Cronbach's alpha value equal to 0.86 .

\section{References}

1. Maslach, C.; Leiter, M.P. The Truth about Burnout. How Organizations Cause Personal Stress and What to Do about It; John Wiley \& Sons: Hoboken, NJ, USA, 2008; ISBN 978-0-470-42356-1.

2. Brittle, B. Coping strategies and burnout in staff working with students with special educational needs and disabilities. Teach Teach. Educ. 2020, 87, 102937. [CrossRef]

3. Dyrbye, L.N.; West, C.P.; Johnson, P.O.; Cipriano, P.F.; Beatty, D.E.; Peterson, C.; Major-Elechi, B.; Shanafelt, T. Burnout and Satisfaction With Work-Life Integration Among Nurses. J. Occup. Environ. Med. 2019, 61, 689-698. [CrossRef] [PubMed]

4. Maslach, C.; Jackson, S.E. The measurement of experienced burnout. J. Organ. Behav. 1981, 2, 99-113. [CrossRef]

5. Leiter, M.P.; Maslach, C. Banishing Burnout. Six Strategies for Improving Your Relationship with Work, 1st ed.; Jossey-Bass: San Francisco, CA, USA, 2005; ISBN 0-7879-7608-3.

6. Burn-out an "Occupational Phenomenon": International Classification of Diseases. Available online: https://www.who.int/ news/item/28-05-2019-burn-out-an-occupational-phenomenon-international-classification-of-diseases (accessed on 21 December 2020).

7. Załuska, U.; Ślazyk-Sobol, M.; Kwiatkowska-Ciotucha, D. Burnout and its correlates-An empirical study conducted among education, higher education and health care professionals. Econometrics 2018, 22, 26-38. [CrossRef]

8. Załuska, U.; Kwiatkowska-Ciotucha, D.; Ślazyk-Sobol, M. Burnout Syndrome as the Example of Psychological Costs of WorkEmpirical Studies among Human-Oriented Professions in Poland. IBIMABR Bus. Rev. 2020, 2020, 1-18. [CrossRef]

9. Świętochowski, W. Wypalenie zawodowe nauczycieli akademickich i nauczycieli szkoły średniej-Analiza porównawcza [Professional burnout among university and high school teachers-Comparative study]. Medycyna Pracy 2011, 62, 133-143.

10. Hämmig, O. Explaining burnout and the intention to leave the profession among health professionals-A cross-sectional study in a hospital setting in Switzerland. BMC Health Serv. Res. 2018, 18, 785. [CrossRef]

11. Chou, L.-P.; Li, C.-Y.; Hu, S.C. Job stress and burnout in hospital employees: Comparisons of different medical professions in a regional hospital in Taiwan. BMJ Open 2014, 4, e004185. [CrossRef] 
12. Nantsupawat, A.; Kunaviktikul, W.; Nantsupawat, R.; Wichaikhum, O.-A.; Thienthong, H.; Poghosyan, L. Effects of nurse work environment on job dissatisfaction, burnout, intention to leave. Int. Nurs. Rev. 2017, 64, 91-98. [CrossRef]

13. Kramer, V.; Papazova, I.; Thoma, A.; Kunz, M.; Falkai, P.; Schneider-Axmann, T.; Hierundar, A.; Wagner, E.; Hasan, A. Subjective burden and perspectives of German healthcare workers during the COVID-19 pandemic. Eur. Arch. Psychiatry Clin. Neurosci. 2020, 1-11. [CrossRef]

14. Hanafin, S.; Cosgrove, J.; Hanafin, P.; Brady, A.-M.; Lynch, C. Burnout and its prevalence among public health nurses in Ireland. Br. J. Community Nurs. 2020, 25, 370-375. [CrossRef]

15. Stevanin, S.; Palese, A.; Bressan, V.; Vehviläinen-Julkunen, K.; Kvist, T. Workplace-related generational characteristics of nurses: A mixed-method systematic review. J. Adv. Nurs. 2018, 74, 1245-1263. [CrossRef] [PubMed]

16. Aiken, L.H.; Sloane, D.M.; Bruyneel, L.; van den Heede, K.; Sermeus, W. Nurses' reports of working conditions and hospital quality of care in 12 countries in Europe. Int. J. Nurs. Stud. 2013, 50, 143-153. [CrossRef] [PubMed]

17. Kutney-Lee, A.; Wu, E.S.; Sloane, D.M.; Aiken, L.H. Changes in hospital nurse work environments and nurse job outcomes: An analysis of panel data. Int. J. Nurs. Stud. 2013, 50, 195-201. [CrossRef] [PubMed]

18. Santinello, M. LBQ. Link Burnout Questionnaire: Manuale; Giunti, O.S., Ed.; Organizzazioni Speciali: Firenze, Italy, 2007; ISBN 9788809402850 .

19. Alameddine, M.; Bauer, J.M.; Richter, M.; Sousa-Poza, A. Trends in job satisfaction among German nurses from 1990 to 2012. J. Health Serv. Res. Policy 2016, 21, 101-108. [CrossRef]

20. Schulz, M.; Damkröger, A.; Heins, C.; Wehlitz, L.; Löhr, M.; Driessen, M.; Behrens, J.; Wingenfeld, K. Effort-reward imbalance and burnout among German nurses in medical compared with psychiatric hospital settings. J. Psychiatr. Ment. Health Nurs. 2009, 16, 225-233. [CrossRef] [PubMed]

21. Schmitz, N.; Neumann, W.; Oppermann, R. Stress, burnout and locus of control in German nurses. Int. J. Nurs. Stud. 2000, 37, 95-99. [CrossRef]

22. Uchmanowicz, I.; Karniej, P.; Lisiak, M.; Chudiak, A.; Lomper, K.; Wiśnicka, A.; Wleklik, M.; Rosińczuk, J. The relationship between burnout, job satisfaction and the rationing of nursing care-A cross-sectional study. J. Nurs. Manag. 2020, 28, $2185-2195$. [CrossRef]

23. Kilańska, D.; Gorzkowicz, B.; Sienkiewicz, Z.; Lewandowska, M.; Dominiak, I.; Bielecki, W. Evaluation of chosen determinants of the positive practice environments (PPE) at Polish nursing wards. Medycyna Pracy 2016, 67, 11-19. [CrossRef]

24. Misiak, B.; Sierżantowicz, R.; Krajewska-Kułak, E.; Lewko, K.; Chilińska, J.; Lewko, J. Psychosocial Work-Related Hazards and Their Relationship to the Quality of Life of Nurses-a Cross-Sectional Study. Int. J. Environ. Res. Public Health 2020, $17,755$. [CrossRef]

25. Haczyński, J.; Skrzypczak, Z.; Winter, M. Nurses in Poland-Immediate Action Needed. Eng. Manag. Prod. Serv. 2017, 9, 97-104. [CrossRef]

26. Bąk-Sosnowska, M.; Gruszczyńska, M.; Tokarz, A. Well-being of nurses and working conditions-Are Polish nurses different from doctors and midwives in terms of professional quality of life? Nurs. Open 2021, 8, 87-95. [CrossRef] [PubMed]

27. Wilczek-Rużyczka, E.; Kwak, M.; Jurkowska, M. Occupational stress and burnout among nurses. Medycyna Ogólna i Nauki o Zdrowiu 2019, 25, 33-39. [CrossRef]

28. Hair, J.F.; Black, W.C.; Babin, B.J.; Anderson, R.E. Multivariate Data Analysis, 7th ed.; Prentice Hall: Upper Saddle River, NJ, USA, 2010; ISBN 978-0138132637.

29. StatSoft. STATISTICA (Data Analysis Software System), Version 12; StatSoft, Inc.: Tulsa, OK, USA, 2014.

30. IBM Corp. IBM SPSS Statistics Base 26; IBM Corp.: Armonk, NY, USA, 2019.

31. Mueller, R.O. Basic Principles of Structural Equation Modeling; Springer: New York, NY, USA, 1996; ISBN 978-1-4612-8455-0. [CrossRef]

32. Schreiber, J.B.; Nora, A.; Stage, F.K.; Barlow, E.A.; King, J. Reporting Structural Equation Modeling and Confirmatory Factor Analysis Results: A Review. J. Educ. Res. 2006, 99, 323-338. [CrossRef]

33. Schulz, M.; Damkröger, A.; Voltmer, E.; Löwe, B.; Driessen, M.; Ward, M.; Wingenfeld, K. Work-related behaviour and experience pattern in nurses: Impact on physical and mental health. J. Psychiatr. Ment. Health Nurs. 2011, 18, 411-417. [CrossRef]

34. Basińska, M.A.; Andruszkiewicz, A.; Grabowska, M. Nurses' sense of coherence and their work related patterns of behaviour. Int. J. Occup. Med. Environ. Health 2011, 24, 256-266. [CrossRef]

35. Kersten, M.; Vincent-Höper, S.; Nienhaus, A. Stress of Dialysis Nurses-Analyzing the Buffering Role of Influence at Work and Feedback. Int. J. Environ. Res. Public Health 2020, 17, 802. [CrossRef]

36. Hinno, S.; Partanen, P.; Vehviläinen-Julkunen, K. The professional nursing practice environment and nurse-reported job outcomes in two European countries: A survey of nurses in Finland and the Netherlands. Scand. J. Caring Sci. 2012, 26, 133-143. [CrossRef]

37. Goniewicz, K.; Goniewicz, M.; Burkle, F.M.; Khorram-Manesh, A. Cohort research analysis of disaster experience, preparedness, and competency-based training among nurses. PLoS ONE 2021, 16, e244488. [CrossRef] [PubMed]

38. Sultan, M.A.S.; Khorram-Manesh, A.; Carlström, E.; Sørensen, J.L.; Sulayyim, H.J.A.; Taube, F. Nurses' Readiness for Emergencies and Public Health Challenges-The Case of Saudi Arabia. Sustainability 2020, 12, 7874. [CrossRef] 
39. Marcinowicz, L.; Owlasiuk, A.; Slusarska, B.; Zarzycka, D.; Pawlikowska, T. Choice and perception of the nursing profession from the perspective of Polish nursing students: A focus group study. BMC Med. Educ. 2016, 16, 243. [CrossRef] [PubMed]

40. Siebens, K.; Casterlé, B.D.d.; Abraham, I.; Dierckx, K.; Braes, T.; Darras, E.; Dubois, Y.; Milisen, K. The professional self-image of nurses in Belgian hospitals: A cross-sectional questionnaire survey. Int. J. Nurs. Stud. 2006, 43, 71-82. [CrossRef] [PubMed] 